\title{
NA GÊNESE DA CONSTITUIÇÃO POLÍTICA DE 1933: O IDEÁRIO CORPORATIVO E A ESTRUTURA ECONÔMICO-SOCIAL DO AUTORITARISMO PORTUGUÊS
}

In the genesis of the Political Constitution of 1933: the corporate ideology and the economic-social structure of Portuguese authoritarianism

En la génesis de la Constitución Política de 1933: la ideología corporativa y la estructura económica y social del autoritarismo portugués

PAULA BORGES SANTOS ${ }^{*}$

http://dx.doi.org/10.1590/\$2178-14942018000200004

\footnotetext{
' Universidade Nova de Lisboa (NOVA FCSH). Lisboa, Portugal.

*Doutorada em História Contemporânea pela Faculdade de Ciências Socais e Humanas da Universidade Nova de Lisboa (NOVA FCSH). (paula.borges.santos@fcsh.unl.pt)

Artigo recebido em 1 de fevereiro de 2018 e aprovado para publicação em 8 de junho de 2018.
} 


\title{
RESUMO
}

A institucionalização do Estado autoritário português teve como principal marco a promulgação da Constituição Política de 1933. Aí se inscreveu o ideário corporativo, que, mais do que tendo um perfil estabilizador, projetou-se como ideal animador do projeto estatal a construir. Envolvendo vários domínios públicos, teve, em toda a vigência do regime, maior importância para o plano da economia. Contudo, permaneceu por estudar como se estruturou o caráter econômico e social daquela Constituição e as negociações políticas que determinaram as opções inscritas naqueles aspectos. Tomando como ponto de partida a reflexão de Jon Elster de que pouco se exploram os processos de elaboração das constituições tanto em estudos sobre casos nacionais quanto em estudos de dimensão comparativa, este artigo procura contribuir para essa temática. Procura-se clarificar como se construiu a dimensão econômico-social da Constituição portuguesa de 1933, atendendo-se às suposições cognitivas dos criadores do texto constitucional, isto é, às crenças que os agentes constituintes apresentaram e que estipularam como sendo os arranjos institucionais capazes de produzir melhores resultados.

PALAVRAS-CHAVE: Estado; Autoritarismo, Constituição; Corporativismo; Organização econômica; Portugal.

\begin{abstract}
The institutionalization of the Portuguese authoritarian state had as its main landmark the promulgation of the Political Constitution of 1933. in which the corporate ideology was inscribed More than having a stabilizing profile, it was projected as an ideal of the state project to be built. Though with a wide regulatory range, the Constitution influenced mainly the economic domain. It remains to be studied how the economic and social architecture of the 1933 Constitution was conceived or which political negotiations explain its final design. Taking Jon Elster's statement that the process of writing a constitution is little explored, both in national case studies and in comparative ones, this article seeks to contribute toward filling in this gap. It will take in consideration the cognitive assumptions of the creators of the Portuguese constitutional text of 1933, as well as their beliefs about the institutional arrangements capable of producing better results.
\end{abstract}

KEYWORDS: State; Authoritarianism; Constitution, corporatism; Economic organization; Portugal.

\section{RESUMEN}

La institucionalización del Estado autoritario portugués tuvo como principal marco la promulgación de la Constitución Política de 1933. En ella se inscribió el ideario corporativo que más allá del perfil estabilizador, se proyectó como ideal inspirador del proyecto estatal que debía construirse. Aunque abarcó varios aspectos públicos, tuvo, durante toda la vigencia del régimen, mayor importancia para el plano de la economía. Sigue sin estudiar cómo se estructuró el cariz económico-social de aquella Constitución y, asimismo, qué negociaciones sirvieron de base para su elaboración. A partir de la reflexión de Jon Elster — quien sostiene que apenas se han explorado los procesos de elaboración de las constituciones, tanto en estudios de ámbito nacional como en los de perspectiva transnacional y comparada —, este artículo busca contribuir al debate sobre el tema, aclarando la génesis de la dimensión económico-social del texto constitucional portugués de 1933, a la luz de las suposiciones cognitivas de los sus autores, es decir, de las concepciones manifestadas y concretadas por los agentes constituyentes, en cuanto arreglos institucionales susceptibles de producir los mejores resultados.

PalabRaS ClaVe: Estado; Autoritarismo; Constitución; Corporativismo; Organización económica, Portugal. 


\section{INTRODUÇÃO: CARACTERÍSTICAS GERAIS DO PROCESSO CONSTITUINTE}

Constituição Política de 1933, que estruturou a fisionomia formal do regime autoritário
Lem Portugal ao longo de toda a sua vigência, definiu novas finalidades para o Estado, em uma dinâmica que permitiu aos decisores políticos e a alguns juristas apoiantes do novo projeto estatal defender que se desenrolava uma nova etapa constitutiva do direito público em Portugal. De certa forma, esse discurso sinalizava um impulso revolucionário que sumariamente se condensava na proposta de fundação de uma "república unitária e corporativa" e se pretendia estabelecer como alternativa à crise da democracia representativa, nos moldes em que tinha sido impulsionada sob a atuação dos governos republicanos de 1910 a 1926.

Nesse ambiente, as condições políticas e práticas de elaboração daquela Constituição não coincidiram com uma conjuntura de pacificação, mas, antes — em uma confirmação da análise de Jon Elster sobre as condições reais de adoção de uma constituição (Elster, 2012: 149) —, com circunstâncias tumultuadas, de negociações duras entre correntes políticas em luta pela liderança da chefia do Estado que só são possíveis de captar, atualmente, com alguma obscuridade, dado não existirem registros documentais que permitam reconstruir, com detalhe satisfatório, a história do processo constituinte que forjou a Lei Fundamental de 1933. Com efeito, a instabilidade política e as desinteligências quanto ao sentido da transformação a efetuar no que se projetava ser a reforma constitucional, equacionada desde os primeiros momentos do golpe militar de 28 de maio de 1926, de que um dos principais rostos foi o do ministro da Justiça e dos Cultos, Manuel Rodrigues Júnior, determinaram a duração dos trabalhos constituintes, justificando sua lentidão, ao contrário do que sustenta alguma historiografia (Chorão, 2009: 528). Na realidade, a questão constitucional fora praticamente herdada no momento de instauração da ditadura militar, já que pouco tempo antes, em janeiro de 1926, o Congresso havia deliberado antecipar em cinco anos a revisão da Constituição de 1911. Em causa estava, especialmente, a reforma do próprio sistema parlamentar, necessidade consensualizada entre o espectro de forças políticas (da Esquerda Democrata ao Partido Republicano Nacionalista) e suportada pelas ideias de racionalização do Poder Legislativo, estabelecimento da representação dos interesses das classes profissionais, mediante uma solução bicameral (com uma câmara eleita por sufrágio direto e outra por sufrágio orgânico) e criação de um Poder Executivo com maiores atribuições.

É conhecido que a Constituição de 1933 resultou de um processo constituinte relativamente longo, tendo em conta a média de preparação de constituições do século XIX e três primeiras décadas do século $X X$, que não excederam os dois anos. Iniciado em meados 
do ano 1930, tanto quanto se pode identificar, e concluído em fevereiro de 1933, tal processo não seguiu nenhuma das variedades tipificadas de "montagem constituinte" (a saber: convenções, legislaturas constituintes mandatadas, legislaturas constituintes autocriadas ou assembleias legislativas autocriadas), tendo tido características de "gabinete". Tratou-se, dito por outras palavras, de um ato constituinte desencadeado pelo Poder Executivo, designadamente nos ministérios de Domingos de Oliveira e de António Oliveira Salazar, no qual teve papel central este último, na qualidade de ministro das Finanças, primeiro, como presidente do Conselho de Ministros, depois. Apesar disso, não se tratou de um caso em que a Constituição tivesse sido essencialmente elaborada por uma única pessoa, como foi o caso da Constituição prussiana de 1848. Ao trabalho de Salazar somaram-se contributos de personalidades de sua confiança política, auscultadas no processo de redação do projeto constitucional, e apreciações de dois órgãos políticos, o Conselho Político Nacional e o Conselho de Ministros. ${ }^{1}$ Saliente-se que, estando o Congresso da República dissolvido por decreto de 9 de junho de 1926, na sequência do golpe militar de 28 de maio desse ano, esse processo constituinte não passou pelas câmaras legislativas, embora tenham sido várias as hipóteses ventiladas envolvendo sua atuação, desde a reabertura do Congresso da República, com manutenção de sua composição, até à convocação de eleições para reunião de uma assembleia constituinte (Araújo, 2007: 88). Nesse aspecto, a Constituição de 1933 encerrou uma experiência constituinte singular em Portugal, já que, ao longo de toda a história do constitucionalismo português, e apenas com a exceção da Carta Constitucional de 1826, ${ }^{2}$ sempre os textos constitucionais foram produzidos por assembleias constituintes. Aquela Constituição é fruto ainda de um dos poucos casos existentes até 2000 de um processo constitucional com origem em um corpo constituinte que não foi um órgão eleito. Tal também ocorreu na Itália, em 1946, e na Alemanha, em 1949, embora com a significativa diferença de essas duas experiências constituintes terem estado associadas ao fim do fascismo e do totalitarismo. Por seu turno, o texto constitucional de 1933 foi produzido no quadro de um sistema ditatorial que pretendia estabilizar-se a si próprio.

0 problema fundamental com que, naquela época, Portugal se confrontava era o da reorganização do Estado, capaz de ser suportada por várias forças políticas, com distintas posições ideológicas, que, apesar de refletirem diferentes graus de compromisso e de identificação, já constituíam uma esfera de apoio dos ministérios da ditadura militar. Ainda que sem a obrigatoriedade de recorrer a um sistema que refletisse essa diversidade política e ideológica, Salazar não descurou a necessidade de se rodear de alguma representação das forças em presença. Tal encontra-se no perfil das personalidades envolvidas no processo constituinte, e, usando novamente a terminologia de Jon Elster, elas não representavam interesse(s), mas detinham (alegadamente) o conhecimento de interesse(s). Foram ouvidas 
figuras proeminentes do Integralismo Lusitano (como Afonso Lucas, Pequito Rebelo ou Hipólito Raposo), para quem era importante a superação das formas representativas liberais; vultos ligados a um pensamento decadentista e nacionalista (Quirino de Jesus); professores de direito da Universidade de Coimbra, influenciados uns pela escola intervencionaista alemã (José Albero dos Reis), outros pela doutrina do institucionalismo francês, sensíveis em maior ou menor grau ao pensamento tomista e à doutrina social católica (Domingos Fezas Vital). 0 envolvimento do Conselho Político Nacional, por meio de uma comissão encarregada de dar parecer sobre o projeto constitucional, permitiu explorar sensibilidades ligadas a um nacionalismo presidencialista, como Martinho Nobre de Melo, profundamente envolvido na Cruzada Nuno Álvares; ao republicanismo de orientação socialista, por intermédio do procurador-geral da República, Francisco Henrique Góis; e a um nacionalismo personalista, singularizado em Mário de Figueiredo. 0 Conselho de Ministros e o próprio presidente da República, também consultados ao longo da preparação da Constituição, diversificaram esses perfis, dado aí pontuarem políticos e militares que conservavam abertura a princípios liberais, conjugando-os com o sentido da hierarquia e salvaguarda da autoridade dos órgãos titulares de poder do Estado (ainda que admitindo a prevalência do Poder Executivo).

Até à submissão do projeto constitucional à discussão da opinião pública, em maio de 1932, por um breve período, foi seguido um regime de sigilo na negociação da Constituição. Após esse período de consulta pública, regressou-se ao trabalho em regime de gabinete, no mesmo restrito circuito da negociação inicial (envolvendo, de novo, os mais importantes órgãos políticos do Estado), até ao momento do plebiscito da Constituição. Essa montagem fechada do texto constitucional gerou um procedimento geral em forma de losango, em que o debate nacional sobre os principais problemas constitucionais ocorreu a meio do processo. ${ }^{3}$ Contrariamente ao que havia sido a condução da questão constituinte por Manuel Rodrigues Júnior, com diversas declarações à imprensa e divulgação de ideias, por exemplo, sobre o desenho do sistema político-institucional a constitucionalizar, o isolamento do legislador constituinte, permitindo escassas notícias sobre o tema e acionando os mecanismos da censura para restringir sua discussão pública, apontava agora para a intencionalidade de não só limitar o impacto das decisões a tomar, como também de reduzir interferências suscitadas por egos pessoais em clima de concorrência. Tal servia ainda a tática de amplificar a ideia de consensualização sobre o que ficava inscrito no texto constitucional.

Apesar dessa configuração da negociação constituinte, o legislador cuidou de impedir o sentimento de alienação popular e não rejeitou consolidar suas opções sobre a ideia de povo, entendido como fundamento do movimento de todo o mecanismo institucional. Tal correspon- 
deu, no entanto, ao que Canales (Canales, 1977: 22), interpretando a teoria da representação europeia nos primeiros anos do pós-Primeira Guerra Mundial, descreveu como sendo uma forma de evitar convocar a soberania popular. Todos os membros do povo formavam uma totalidade que se identificava como vontade superior, a vontade nacional, a qual, por sua vez, era determinada por considerações superiores do interesse geral. Apenas a essa luz, aliás, pode-se entender a opção por plebiscitar a Constituição, o que veio a suceder em 19 de março de 1933. De fato, por essa via, era devolvido àquele sujeito político — tido como o conjunto dos governados — o pronunciamento de maneira definitiva sobre o que constava na Constituição, sem que tal assentasse na concepção meramente representativa da democracia. Partindo da noção de associações naturais na sociedade — a família, a corporação e as autarquias locais — o povo era considerado o ente primário de formação da estrutura da nação que o Estado organizava e, portanto, agente impulsionador da construção constitucional e também responsável pela validação do ordenamento constitucional. Do ponto de vista do que se inscrevia na Constituição formal, tal visão levava a considerar o direito dos cidadãos individuais (dos governados), ainda que sob elevada regulamentação, patente na remissão para leis especiais do exercício de várias liberdades, na proibição de greve, na extensão do sufrágio ou na ausência de referências aos partidos políticos.

\section{A ORDEM SOCIAL E ECONÔMICA INSCRITA NA PRIMEIRA EDIÇÃO DO PROJETO CONSTITUCIONAL}

dificuldade em satisfazer as aspirações das diferentes forças políticas exigiu que se
Lencontrasse um elemento de homogeneidade capaz de ser partilhado, o qual se pode dizer que recaiu em uma concepção organicista de Estado. Todavia, as divergências no modo de conceber sua fundamentação e sua concretização não trabalharam como fator efetivo de coesão, e o modelo de Constituição produzido foi compósito, sem uma fisionomia clara e bem-definida. Consultando as nove edições preparatórias do que veio a ser o texto final da Constituição de 1933 (algumas delas contendo mais do que uma cópia com anotações manuscritas $^{4}$ ), fica claro que, desde a redação do primeiro esboço de estatuto constitucional, houve a opção de desenvolver a ideia corporativa em um âmbito amplo de matérias, relacionadas quer com as garantias fundamentais (Parte I do projeto constitucional e também do texto final da Constituição), quer com a organização política do Estado (Parte II, igualmente do projeto e da Constituição).

Por já ter sido um tema explorado em outras investigações (Araújo, 2007: 17-119), não se discutem aqui as várias propostas sobre o desenho do sistema político concebidas para a 
Parte II do projeto constitucional, merecendo apenas que se saliente que a consulta das várias edições demonstra como os títulos relativos aos órgãos de soberania (presidente da República, governo e Assembleia Nacional), e ainda à Câmara Corporativa, foram dos mais modificados, da primeira à última versão. Para as alterações introduzidas, designadamente no tocante à natureza dos sufrágios, contribuíram algumas reações críticas das personalidades auscultadas. Assim, o legislador recuou no sufrágio misto para eleição da Assembleia Nacional, optando por instituir o sufrágio direto. A eleição do presidente da República passou também a fazer-se por voto direto dos cidadãos com capacidade eleitoral, e não só dos chefes de família. Não sendo aqui o lugar para discutir a teoria da representação política que suportou essas escolhas, deve-se, contudo, sublinhar que o sufrágio direto, inscrito no texto constitucional, passou a assentar-se em novos fundamentos, distanciados dos puramente liberais. Estando o pensamento do legislador familiarizado com as teorias alemãs de Gierke, Laband e Jellinek, mas próximo especialmente das teses institucionalistas de Maurice Hauriou e Léon Duguit (Sousa, 1907: 30-38; Vital, 1940: 433), é plausível admitir-se que, com a consagração do sufrágio, não se pretendesse exagerar o papel da eleição, vista apenas como procedimento empírico de designação dos representantes do povo (Canales, 1977: 32-33). Essa posição ajuda a explicar o desvirtuamento dos atos eleitorais que 0 Estado Novo seguiu na prática, criando eleições não concorrenciais. Aí, assistiu-se à desvalorização dos sufrágios, cuja função consistia apenas em conferir ao eleito uma investidura em nome da soberania nacional.

Quanto à Parte I, o referencial organicista encontra-se nos preceitos dos Títulos I a XIV, sobre a nação, a família, as corporações e as autarquias, as corporações morais e econômicas, e a ordem econômica e social. Aí, tomava forma a consideração do cidadão em sua vida social, em seus interesses econômicos e educativos, o que correspondia a uma regulação constitucional que, depois da Constituição de Weimar, começara a influenciar o constitucionalismo de pequenos Estados europeus e se caracterizava por um intervencionismo estatal e por uma extensão de direitos a determinadas instituições sociais ou a coletivos dotados de personalidade (Mortati, 2010 [1946]: 49-52). Essa evolução captara a atenção de Salazar, que a apelidou de "formação de um vínculo econômico e social de natureza constitucional", sendo favorável à introdução no texto da Lei Fundamental de "matérias de caráter econômico e social", com "desenvolvimento e semelhança neste ponto a constituições como a de Weimar". O projeto constitucional português deveria, todavia, ser original em relação a esse modelo, dando "mais desenvolvimento e precisão" a "muitos problemas", mas também dando outra ordem "mais clara e superior" às matérias. ${ }^{5}$ 
Dentro desse espírito, o legislador constituinte atribuiu, logo na primeira edição do texto constitucional, direitos:

- À família, considerada "elemento político primário" e com direito reconhecido a educar os filhos. Sob especial proteção da Constituição era colocada a situação econômica da família, fixando-se o compromisso de que os impostos seriam regulados tendo em conta os encargos familiares, de se favorecer a constituição de lares independentes e em condições de salubridade. Com caráter de diretiva para 0 futuro, estabelecia-se que seria promovida a adoção do salário familiar, a proteção à maternidade e a cooperação (do Estado com a família) na educação dos filhos (em estabelecimentos de ensino tanto públicos quanto privados). A coesão familiar era um valor a preservar, integrante da moralidade pública (católica), como indicavam as disposições que exigiam que a família se assentasse no casamento, obrigatoriamente registrado (tal como se exigia ao nascimento dos filhos), e na diferença de direitos estabelecidos para filhos legítimos e ilegítimos.

- À freguesia, aos municípios e agrupamentos de municípios, considerados como detentores de direitos políticos.

- Às corporações morais e econômicas, cuja organização deveria ser promovida pelo Estado, e onde tinham representação orgânica, para efeitos políticos, todos os elementos da nação. Cabia-Ihes tomar parte na eleição do presidente da República, dos membros das câmaras legislativas, dos conselhos de província e das câmaras municipais. As corporações morais seriam especialmente políticas, científicas, literárias e artísticas, técnicas, de assistência e de beneficência. Admitia-se poder a lei vir, no futuro, a aceitar as de funcionários públicos. As corporações econômicas seriam de proprietários urbanos e rurais, agricultores, industriais, comerciantes, de empregados do comércio, indústria e agricultura, de artes e ofícios e de trabalhadores.

Reconheceu-se o direito à propriedade e à sua transmissão hereditária, nas condições determinadas pela lei civil. Fixava-se ainda que a propriedade, a par do capital, tinha uma função social, que podia sujeitar "o direito pleno do capitalista ou proprietário à condição do emprego ou exploração em termos justos e conformes com as finalidades coletivas" . A representação sindical era também reconhecida, considerando-se as associações sindicais de "portugueses de ambos os sexos e de pessoas jurídicas portuguesas, e bem assim de federações e confederações gerais e nacionais". Aquelas associações, desde que legalmente reconhecidas, tinham a possibilidade de celebrar contratos coletivos de trabalho. Todos os contratos, feitos sem tais associações, seriam considerados nulos. Cabia ainda às associações sindicais regular 
a conflitualidade entre as entidades associadas, estimular e subsidiar suas iniciativas que visassem a organizar a produção, instituir "estações de emprego". Não se admitia o direito à greve. Estabelecia-se que tribunais especiais de apelação, organizados como juízes de arbitragem, julgariam os litígios relativos às relações coletivas de trabalho. Consagrava-se a liberdade de escolha de profissão ou gênero de trabalho, indústria ou comércio. No entanto, essa liberdade não era plena nem efetiva, já que ficava sujeita às restrições impostas pelo bem comum e a exclusivos que o Estado e os corpos administrativos entendessem conceder. $A$ questão da liberdade sindical era aqui omitida, embora se depreendessem fortes limitações ao direito de associação (totalmente assumidas na edição definitiva da Constituição), como era manifesto na proibição do direito à greve.

No plano econômico (Título VIII: Da ordem econômica e social), naquela primeira edição, o Estado assumia a responsabilidade de:

- Coordenar e regular a vida econômica na metrópole e nas colônias. Cabia-Ihe ainda a fiscalização das relações de "circulação, distribuição e consumo de riqueza". Admitia-se que o Estado organizaria diretamente atividades econômicas, "se os particulares não se resolvem a exercê-las por desvantagem de rendimento ou por outros motivos". Previa-se também que o Estado impusesse as "limitações adequadas" quando uma atividade privada custasse mais do que outras que rendessem tanto ou mais do que ela.

- Defender o interesse coletivo em conflitos com terceiros, que em sua condução de "explorações agrícolas, industriais e comerciais" revelassem "caráter parasitário", evitando "concorrências desregradas". Admitia-se, na mesma linha, que as associações e os interesses econômicos particulares pudessem ter de se subordinar às "superiores necessidades nacionais".

- Assegurar as políticas de preços (o menor preço) e salários (o maior salário), apontadas a ideias de solidariedade e de justiça social (o maior lucro justo).

- Prover as "classes trabalhadoras", especialmente "o menor e a mulher". Esse aspecto articulava-se com o ponto anterior, na medida em que remetia à ideia de uma distribuição de riqueza pelas classes envolvidas nas atividades produtivas. Não se esclarecia, no entanto, qual a forma de intervenção do Estado ou de outras entidades para atingir aquela finalidade.

- Garantir a alimentação e a saúde pública, estabelecendo-se a criminalização de ações que se fizessem contra elas. 
- Promover as instituições de solidariedade, previdência, cooperação, mutualidade e assistência, não se esclarecendo se tal seria feito a título subsidiário ou se seria uma intervenção principal do Estado.

Uma noção de igualdade distributiva, ainda que com sentido negativo, encontrava-se nas disposições que determinavam que seriam impedidas, ou alvo de "tributações adequadas", as excessivas acumulações de lugares e cargos em sociedades, empresas comerciais e industriais. Também se assumia organizar o crédito, visando à sua distribuição por todos os agentes da vida econômica. Como limite à intervenção do Estado nesse domínio, determinava-se que nunca poderiam ser objeto de consolidação forçada tanto a dívida flutuante do Estado quanto os débitos por depósito efetuados nas caixas do Estado ou de estabelecimentos de crédito que Ihe pertencem. Essa disposição seria, em edições seguintes do projeto constitucional, transferida para o título relativo às finanças do Estado.

É interessante notar que esse último título (à época Título XIII, futuro Título XIV), complementar à estrutura econômica da Constituição, foi dos mais modificados logo na primeira edição do projeto constitucional, adquirindo logo aí uma redação quase definitiva. Com efeito, não voltou a sofrer alterações de redação senão na nona edição da Constituição, na qual se introduziram referências às colônias e se atualizou o nome da câmara política. A documentação revela que foi Salazar o autor dessas alterações, redigindo novos preceitos nas margens do documento. A principal diferença envolveu a autonomia do ministro das Finanças. 0 projeto inicial previa sua subordinação, em especial à Câmara dos Deputados e ao Congresso, mas também ao Tribunal de Contas, mediante a obrigação daquele titular de apresentar àquela Câmara o orçamento geral do Estado nos primeiros 15 dias de fevereiro; a permisão de o Congresso reduzir ou rejeitar os créditos orçamentais que lhe fossem propostos; antes do encerramento da sessão legislativa, a permisão de o Congresso autorizar o governo a cobrar receitas do Estado e pagar despesas públicas na gerência futura, defendendo ainda, na mesma lei, os princípios a que deveria subordinar-se o orçamento no tocante a despesas cujo quantitativo não fosse determinado de acordo com leis preexistentes; a permisão de fazer depender da aprovação do Poder Legislativo o orçamento para a nova gerência, obrigando, em caso de não aprovação, o Conselho de Ministros a estabelecer um orçamento provisório para vigorar até à entrada em execução do definitivo; a apresentação da conta anual de receitas e despesas do Estado a submeter ao Congresso pelo titular das Finanças; a obrigação do Tribunal de Contas de examinar a conta anual de receitas e despesas do Estado, dirigindo ao Conselho de Ministros e ao Congresso o relatório de seu trabalho, cujas conclusões seriam posteriormente apresentadas pelo governo ao Congresso. 
Salazar eliminou todas essas disposições, salvaguardando para o titular das Finanças uma atuação independente do pronunciamento do Poder Legislativo. Recorrendo a uma simplificação substantiva do número de preceitos nesse título, definiu que o orçamento geral do Estado seria anualmente organizado e posto em execução pelo governo, admitindo apenas que tal fosse feito em conformidade com a lei de autorização dada pela Câmara dos Deputados. Somente a cobrança de impostos estabelecidos por tempo indeterminado ou período que ultrapassasse uma gerência ficava dependente da autorização do Congresso.

\section{AS PRINCIPAIS MODIFICAÇÕES RELATIVAS À ESTRUTURA ECONÔMICA E SOCIAL DO PRIMEIRO PROJETO CONSTITUCIONAL}

E ntre a primeira e a segunda edição do projeto constitucional, registra-se uma preocupação do legislador de clarificar a redação da generalidade das disposições do Título VIII. Esse trabalho não terá sido feito por Salazar, já que a letra manuscrita nessa edição, que introduz as várias alterações, não é sua. Do que foi possível apurar, terá sido Quirino Avelino de Jesus seu autor, pois a caligrafia corresponde àquela que forma outros escritos seus, encontrados nas pastas nas quais estão arquivadas as várias edições do texto constitucional. A principal alteração feita envolveu as associações sindicais, suprimindo-se as finalidades a que poderiam obedecer. Foi ainda ponderada a hipótese de se eliminar o encargo que lhes cabia de celebração dos contratos coletivos de trabalho; todavia, depois de ser cortado, voltou-se a decidir que "Fica". Suavizaram-se as restrições a impor à acumulação de cargos em empresas comerciais e industriais. Por fim, a última alteração textual substantiva envolveu a dívida flutuante do Estado, que deixava de ser mencionada entre o que não podia ser objeto de consolidação forçada.

Bastante alterado por Salazar foi o Título V, dedicado às corporações morais e econômicas. Todos os artigos aí contidos sofreriam uma reelaboração. Atenuava-se o papel do Estado quanto à formação das corporações morais e econômicas, bastando indicar que apenas as reconhecia, promovia e auxiliava, procedendo da mesma forma para com as associações sindicais. Desaparecia a referência à possibilidade de constituição de corporações de funcionários públicos. Mantinham-se os objetivos políticos, científicos, literários e artísticos, de assistência, beneficência ou caridade, de aperfeiçoamento técnico ou solidariedade de interesses das corporações. Inovava-se, contudo, ao determinar que seriam reguladas em sua constituição e exercício pelas "normas especiais das leis associativas".

Na edição seguinte do projeto constitucional, registram-se novas alterações de pormenor de redação no Título VIII, merecendo apenas assinalar que aí se abandonou a ideia de 
criminalizar ações que atentassem contra a alimentação e a saúde públicas. Será na quarta edição, que incluiu as emendas aprovadas em reunião de Conselho de Ministros de janeiro de 1932 e outras feitas na sequência de revisão do texto com essas emendas, que se encontram modificações ao Título VIII dignas de nota. Abandonava-se o preceito que garantia que a economia portuguesa obedeceria ao princípio da harmonização com outras nações, ainda que podendo admitir modalidades especiais em relação a certos Estados. Dava-se nova redação à disposição reguladora da relação do Estado com as atividades econômicas privadas. Retirava-se a ideia de limitar as pouco rentáveis, substituindo-a pela ideia de favorecimento das mais rendosas, com admissão da possibilidade de proteção e beneficio social a dispensar às pequenas indústrias domésticas. Foi também eliminada a ideia de crimes e de penalizações de ações que atentassem contra a alimentação e a saúde públicas. Sobre os tribunais especiais a criar para litígios que envolvessem as relações coletivas de trabalho, caía a designação de que seriam "de apelação". Alteração substancial dava-se com a passagem da celebração dos contratos coletivos de trabalho das associações sindicais para as corporações econômicas (opção que ficaria inscrita no texto final da Constituição). Eliminava-se, em definitivo, o preceito que previa a subordinação da organização do crédito à necessidade de sua distribuição por todos os concorrentes da vida econômica.

Em matéria das finanças do Estado, no Título XIV, com redação já praticamente estabilizada, introduzia-se um parágrafo único, que previa que cada uma das colônias viesse a organizar seu orçamento. Em matéria de impostos, também se fixava que a lei determinaria a matéria de incidência, a taxa e isenções a que houvesse lugar, admitindo-se reclamações e recursos em favor do contribuinte. Mudanças significativas foram inscritas ainda no Título V, que nessa edição passaria a ser o IV (como, aliás, veio a ficar na versão final do texto constitucional). Pela primeira vez, eliminava-se a ideia de que nas corporações morais e econômicas, bem como nas associações ou organizações sindicais, teriam "representação orgânica, para efeitos políticos, todos os elementos da Nação". Retiravam-se também os objetivos políticos às corporações, associações ou organizações. Por último, uma alteração substantiva: era eliminado o preceito que admitia que as corporações ou organizações recenseadas tomassem parte na eleição do presidente da República, câmaras legislativas, conselhos de província e câmaras municipais. Na globalidade, todas as modificações feitas nessa versão do projeto constitucional comprovam o papel importante de modelagem dos conteúdos constitucionais que teve o Conselho de Ministros, ao que acresce uma forte mitigação da dinâmica da representação orgânica e um esvaziamento da dimensão política das corporações morais e econômicas.

Entre a produção da quarta e da sexta edição do projeto constitucional, haveriam de decorrer dois escassos dias, o que indica que houve uma concentração do trabalho constituin- 
te no mês de fevereiro de 1932. Na elaboração da sexta edição, segundo os apontamentos inscritos na documentação, Salazar trabalhou com Domingos Fezas Vital e Martinho Nobre de Melo. São muitas as alterações em todo o articulado do texto constitucional, sobretudo em títulos que não são analisados neste artigo. Ainda que não existam elementos que esclareçam suficientemente o porquê desse labor mais intensivo do legislador, é plausível pensar que tal se prendia à necessidade de submeter nova edição do projeto constitucional ao Conselho de Ministros, como veio a ocorrer em 5 de março de 1932. Nas matérias que aqui se acompanham, cumpre salientar uma modificação no artigo que reconhecia o direito de propriedade e sua transmissão, particularizando-se que esta deveria ser por testamento ou herança (não bastando, como até aí, dizer-se que seria por transmissão hereditária). Sobre as corporações morais e econômicas, voltava-se atrás quanto a serem reguladas por "normas especiais das leis associativas", inscrevendo-se uma fórmula mais vaga que remetia simplesmente para sua regulação por "normas especiais". No título dedicado à família, às corporações e autarquias como elementos políticos, assinalavam-se várias interrogações quanto à participação das corporações em eleições, não sendo fixado quem elegeria o quê. No Título VIII, a par de melhorias de redação, duas alterações substantivas foram feitas. Uma, que particularizava que só as corporações econômicas, reconhecidas pelo Estado, poderiam celebrar contratos coletivos de trabalho. Outra, que tornava mais clara a forma de intervenção do Estado na gerência das atividades econômicas particulares, quando houvesse que financiá-las. Estipulava-se que tal deveria ocorrer "para conseguir benefícios sociais superiores aos que seriam obtidos sem a sua intervenção". Em vésperas do Conselho de Ministros, Salazar e Fezas Vital voltaram a introduzir alterações no texto constitucional, naquela que foi sua sétima edição. Aí se fixou definitivamente a garantia do direito de propriedade e sua transmissão "em vida ou por morte, nas condições determinadas pela lei civil", abandonando-se os institutos da herança ou do testamento. A oitava edição do projeto constitucional recolheu melhoramentos de redação.

Aparentemente, foi só um ano depois, entre 14 e 20 de fevereiro de 1933, que o legislador constituinte, dessa vez por intermédio da dupla Salazar e Fezas Vital, voltou a fazer correções ao projeto constitucional naquela que foi uma revisão de redação profunda e onde se manifestam ainda muitas dúvidas que atravessam todo o articulado. Tratando-se da nona edição, a verdade é que esta é composta por quatro versões. Assim, em sua primeira versão (que envolveu as Partes I e II da Constituição), insere-se no Título IV, pela primeira vez, que o Estado não reconhece as corporações ou organizações que "assentem ou admitam o princípio da luta de classes". Já no Título V se fixou em definitivo que as corporações morais e econômicas tomariam parte na eleição das autarquias, conselhos de província e Câmara Corporativa. Por sua vez, as juntas de freguesia elegiam as autarquias, e estas, os conselhos de província. 
Na Câmara Corporativa, haveria representação das autarquias locais. Na terceira versão (que só envolveu a Parte I) da nona edição, modificou-se uma das disposições mais antigas do projeto ao estabelecer que o capital e o trabalho (este último substitui a propriedade, que era eliminada) desempenhavam uma função social, em "regime de cooperação econômica e de solidariedade". Também deixava de se referir que o trabalho era "elemento de cooperação da empresa econômica, podendo ser-lhe associado", para mencionar que, "quer simples, quer qualificado ou técnico pode ser associado à empresa".

Para a quarta versão da nova edição, que envolveria a revisão finalíssima das Partes I e II, estava, contudo, reservada a alteração que condicionou todo o desenvolvimento do Estado Novo e que tem merecido ampla atenção de todos os estudiosos que têm trabalhado o regime. Com efeito, no artigo que aí ficou definitivamente identificado como artigo 5, onde se lia o Estado português "é uma República", Salazar, por seu punho, acrescentou "unitária e corporativa".

Tratava-se, na realidade, de uma precisão de última hora. Aquele artigo, que até então fora sempre o número seis, tivera na primeira edição do projeto constitucional a seguinte fórmula: "O Estado é organicamente democrático e representativo." Na segunda edição, ser- Ihe-ia dada nova redação: "A forma de governo do Estado é a república, organicamente democrático e representativo." Nas edições seguintes, haviam-se seguido pequenas reformulações nessa redação. Todavia, na altura, existia um artigo 5으, redigido por Quirino de Jesus e eliminado durante a produção da segunda edição da Constituição, no qual se lia:

O Estado é liberal, social e corporativo. Reúne, coordena e harmoniza na sua organização política os cidadãos, com as suas garantias e direitos individuais; a sociedade, com os seus interesses superiores, aos quais aqueles estão subordinados; e a família, as autarquias regionais e locais e as corporações morais e econômicas, com as suas imunidades, resultantes da natureza ou da lei.

Ao dar aquela redação final ao que ficou sendo o artigo 5ㄴ, Salazar aproximava-se do espírito da fórmula sugerida por Quirino de Jesus, embora evitando ser prolixo. Ao fazê-lo, por um lado, convocava o consenso existente entre os atores envolvidos no processo constituinte quanto a conceber a organização do Estado à luz de uma concepção organicista. Por outro, o uso do referencial corporativo como princípio ordenador servia-Ihe para envolver as novas adaptações feitas ao direito público português, constitucional em especial, em uma aura de modernidade. ${ }^{6}$ Por outras palavras, tratava-se, em boa medida, de recorrer a uma etiqueta política que começara a fazer furor na Europa (Espanha, França, Suíça, Áustria, Alemanha e Itália), na composição de respostas à crise econômica de 1929 e à crise política da década de 1930, ainda que por meio dela exprimissem diferentes aspirações, como o apelo a uma coexis- 
tência pacífica entre capital e trabalho; o combate ao marxismo; o desenvolvimento de novas formas de regulação econômica e social (Rosanvallon, 2007 [2004]: 328; Cuevas, 2013: 631 637). Como Salazar haveria de mencionar, o corporativismo era o ponto de contato do "nacionalismo português" com sistemas políticos internacionais da época (Salazar, 1935: 334). ${ }^{7}$

Pode-se admitir, com facilidade, a partir do que o próprio governante revelara até então serem suas ideias econômicas, que sua definição da República como corporativa não remetia a uma posição teórica robusta. Como já foi sublinhado por Brandão de Brito, nesse domínio, Salazar era no essencial um pragmático, defensor de uma doutrina heteróclita, buscando fundamentação para as reformas que preconizava nos fatos concretos da realidade nacional. ${ }^{8}$ Donde quer seus diagnósticos da debilidade estrutural do aparelho produtivo português, que associava à persistência de um elevado deficit comercial e à "alta remuneração do trabalho", quer as soluções de reforma do sistema financeiro ou a defesa da solidez das instituições, da natureza relativamente secundária da indústria, do papel fundamental da agricultura, da correção dos canais de distribuição e da unificação do mercado interno, de diferenciação salarial (por setores e regiões) e negociação generalizada entre patrões e trabalhadores visassem a atingir um único fim: introduzir na economia, pela intervenção estatal, "segurança" (defendendo-a tanto dos "excessos do capitalismo quanto do bolchevismo destruidor"), subordiná-la às finanças e alcançar uma "mediania regular" (a nação deveria bastar-se a si própria, produzindo o necessário para o consumo) (Brito, 1989: 39-54). Não surgindo tais ideias ancoradas em um conceito fechado de corporativismo, com uma forte componente normativa e ideológica.

\section{EXPANSÃO E LIMITES DO REFERENCIAL CORPORATIVO PARA O LEGISLADOR CONSTITUINTE DE 1933}

e, entre os atores envolvidos no processo constituinte, como antes se sublinhou, foi
consensual conceber a organização do Estado à luz de uma concepção organicista, cumpre registrar que se observaram discordâncias entre si sobre a amplitude com que se deveria consagrar essa ideia corporativa, designadamente quanto à sua dimensão econômica e social. Um dos integralistas auscultados, Afonso Lucas, mostrou-se reticente quanto a escrever-se uma "Constituição corporativista antes do País estar organizado em corporações". Pugnou pela constituição de conselhos corporativos junto de cada ministério e, em particular, de um Conselho Econômico, junto de um Ministério da Economia. Esses conseIhos deveriam vir a "dar uma efetiva Assembleia Nacional". Lamentou que nada impedisse a existência de "sindicatos marxistas e outras organizações socialmente nocivas", defen- 
dendo que não se aceitassem "corporações ou agremiações que se baseiam no princípio da luta de classes nem as que tendam à luta civil dos partidos, nem as que dependam de seitas secretas". Sua crítica envolvia ainda o que considerava ser a fraca afirmação do "caráter social do regime", dado que não se mencionava a "assistência aos mínimos". Apesar de ter outro posicionamento ideológico, também José Alberto dos Reis revelou insatisfação por não se acentuar bastante o "caráter social" do texto constitucional. Discordava de se deixar subentender a "oposição das classes em economia" e de "certo exagero de intervencionismo de Estado na definição das suas funções econômicas". Para Mário de Figueiredo, vários preceitos do Título VIII tinham formulação demasiado vaga. Propunha eliminar referências à livre concorrência, porque, ainda que fosse "inofensivo", tinha um "ar individualista contrário às tendências do nosso tempo". Mostrar-se-ia particularmente crítico da forma de intervenção do Estado na gerência das atividades econômicas particulares, sugerindo que incidisse na capacidade de fiscalização do Estado. Pretendia ver introduzido o princípio da expropriação. ${ }^{9}$ Sem ser possível precisar a data desses comentários, é de admitir que tenham resultado de consultas feitas sobre as propostas da segunda e quarta edições da Constituição. Nenhuma das observações foi acolhida pelo legislador.

0 principal autor da primeira edição de projeto constitucional, Quirino de Jesus, não obstante as modificações a seu projeto, defendeu publicamente o sentido das opções fixadas, evocando, em razão do seu argumento, autores com um pensamento tão diferenciado quanto Le Play e Sorel (Jesus, 1932: 151-157).

As propostas de Martinho Nobre de Melo sobre o modo como o Estado deveria administrar a economia e os recursos naturais do território português não tiveram acolhimento direto no texto constitucional. Porém, é importante notar a sintonia de sua posição com a do legislador sobre a relação do Estado com as entidades privadas, podendo admitir-se que tenha tido aí alguma capacidade de influência (não tanto sobre Salazar — que manifestará, especialmente em reunião do Conselho Político Nacional e em anos futuros, ter essa convicção bastante arreigada, resistindo, por exemplo, a pressões de setores católicos para dotar obras confessionais, educativas e assistencialistas, de apoio financeiro - mas entre os demais protagonistas constituintes). Defendia o antigo ministro que, nesse horizonte, a função do Estado era de "auxílio e tutela", completando a "iniciativa privada insuficiente, em um esforço "supletivo" (Araújo, 2007: 202; Melo, 1925: 56). No Conselho Político Nacional, Melo, ao contrário dos que julgavam precipitado aprovar a Constituição sem estarem organizadas as corporações, como era o caso de Mário de Figueiredo, também secundou Salazar na determinação de ser oportuno promulgar a Lei Fundamental (Araújo, 2007: 195-196). 


\section{CONSIDERAÇÕES FINAIS}

E m síntese, do que fica exposto, pode-se concluir que houve forte variação nos preceitos da estrutura econômico-social da Constituição entre o que foi sua primeira versão e a última. As fontes disponíveis no momento de redação deste artigo não permitem esclarecer satisfatoriamente como se processou a negociação no interior do núcleo constituinte sobre o que firmar naquela dimensão da Constituição. Em especial, fica por clarificar o teor do debate político travado no seio do Conselho de Ministros, sendo, porém, inequívoca sua importância no processo e na construção de algumas opções (por exemplo, sobre o organismo que deteria a competência da celebração dos contratos de trabalho, ou sobre a organização do crédito e de sua distribuição).

A investigação conduzida concorre, no entanto, com o que foi possível averiguar para matizar a ideia de Salazar como figura do legislador preponderante e sem contraditório. Registra-se nos contributos que deu para a construção do texto constitucional uma dicotomia, que se refletia em sua própria condução, primeiro como acadêmico e depois como ministro: maior firmeza no pensamento sobre as finanças do Estado do que sobre aspectos econômicos. Não por acaso, as alterações que muito cedo introduziu nas disposições ditas financeiras não sofreram modificações (a não ser no que envolvia o desenho do Poder Legislativo evocado nesses preceitos, matéria em que, saliente-se, Salazar não fez nenhuma escolha ou imposição relevante que seja hoje conhecida, parecendo antes que terá apostado na conciliação de posições dos constituintes). Destaque-se ainda sua postura comedida quanto a temas caros aos interesses históricos da Igreja Católica e ao pensamento social da doutrina pontifícia, no tocante à dimensão corporativa a construir, como o envolvimento do Estado na proteção material das classes trabalhadoras, na promoção da assistência, na defesa da instituição familiar. Não sendo possível afirmar, por falta de provas empíricas mais substantivas, que foi Salazar quem recusou a consagração das fórmulas que explicitamente favoreciam ou exaltavam essas dimensões, é, todavia, factível que não se ocupou de secundá-las e/ou fazer aprová-las a qualquer custo político. Esse comportamento ganha coerência à luz do que veio posteriormente a ser sua política para com a Igreja Católica, em que manifestou o entendimento de que cabia ao Executivo o papel preponderante na regulação da expressão social do fenômeno religioso (Santos, 2016: 509-510), e é relevante para contestar o argumento, defendido por vários autores, de que a modelagem da Constituiç̧ão se fez com soluções sustentadas pelos setores católicos e integralistas (Schmitter, 1999: 109, 116, 166, 166 e 169; Rosas, 2012: 18-20).

Sobre os últimos, representados nas posições antes identificadas de Afonso Lucas e Pequito Rebelo, seus contributos em matéria econômica não foram acolhidos pelo legislador. 
Pode-se afirmar, mesmo sem se conhecer o argumentário que correspondeu à decisão de não aproveitar suas propostas, que não interessou ao "gabinete" constituinte seguir uma proposta de corporativismo favorável a um padrão de elevada relação institucional entre centros de tomada de decisão política e os interesses organizados (como pressupunham a criação dos conselhos corporativos ou a instituição do Conselho Econômico). Posição curiosa teria Alfredo Pimenta, que, apresentando as bases que adotaria para modificar a Constituição de 1911, não dedicou uma linha à organização econômica e social, admitindo ainda que, do estatuto constitucional apresentado pelo Ministério de Domingos de Oliveira, apenas aproveitaria o Título I (Pimenta, 1932: 1 e 6).

Quanto aos católicos, note-se que vários dos constituintes eram sensíveis à cultura católica (dos integralistas até aos professores Domingos Fezas Vital e José Alberto dos Reis, este último maçônico), que conheciam com diferentes graus de aprofundamento, e alguns tinham participação no Centro Católico Português (Mário de Figueiredo e o próprio Salazar), mas nenhum pode ser considerado defensor ou porta-voz dos interesses específicos da Igreja Católica naquele contexto. Também o cotejamento da imprensa católica sobre a recepção do projeto constitucional ao longo do verão de 1932 e, mais tarde, do texto final da Constituição, em fevereiro de 1933, revela um diminuto entusiasmo em relação à ideia corporativa, em boa medida decorrente do que se denunciou ser sua artificialidade para a realidade portuguesa e a alegada "falta de prática de vida associativa" (Guerra, 1932: 1). De tal modo que nem chegariam à elaboração propostas concretas, úteis à construção da dimensão econômica e social do texto constitucional. Apenas se registram duas exceções, uma que recaiu na defesa da associação livre na profissão organizada, e ainda assim feita indiretamente, mais para citar um projeto de reforma constitucional patrocinado em 1927 por d. Manuel II do que para contrapor ao assinalado no projeto constitucional (Sousa, 1932: 1), e outra, que solicitava maior clareza sobre o que poderia vir a ser a intervenção do Estado no "serviço industrial", exigindo garantias que obstassem à nacionalização de indústrias, como a elétrica (Cerqueira, 1932: 6). Mais comuns foram as reações críticas ao intervencionismo estatal que se projetava no texto constitucional, apoiadas na retórica da doutrina pontifícia sobre o papel do Estado e em seu dever de cooperação com os privados. Foram ainda alvo de contestação a indefinição de organização para o "sindicalismo nacional operário", o reconhecimento de direitos aos filhos ilegítimos e a opção por formas transitórias para enformar a representação orgânica enquanto não se constituíssem as corporações (Couceiro, 1932: 8; Sousa, 1933: 1). ${ }^{10}$

Na evolução do que foi a elaboração da Constituição, em sua estrutura econômico-social, observa-se a mitigação de uma ambição inicial que abria caminho à participação 
contínua e estruturada dos interesses organizados nas áreas decisórias do Estado, isto é, na elaboração de políticas e em sua implementação. As soluções adotadas por fim repousaram em uma convergência em torno dos seguintes pressupostos, interligados entre si e de difícil hierarquização: i) superação do princípio individualista e afirmação da prioridade do social; ii) elevação da economia a interesse público, ou seja, a interesse do Estado; iii) consagração de uma ampla margem de intervenção do poder estatal na gestão da economia; e iv) subordinação do interesse coletivo, interpretado e definido pelo Estado, a uma ideia de finalidade espiritual da nação, também ela interpretada e definida pelo Estado e que andou de par com a ideia da moral pública. Em boa medida, a noção de igualdade convocada no articulado da Constituição, em várias de suas disposições - distinta do esquema habitual do século XIX, que pressupunha que se buscava o tratamento idêntico dos indivíduos entre a lei ou a justiça — , parece remeter a essa dimensão moralizante ao apontar para a criação de condições necessárias que a todos beneficiassem. Nesse aspecto, como em outros, as disposições constitucionais não requeriam uma resposta imediata, mas apontavam para respostas teóricas que exigiam a renovação da estrutura econômica.

De fato, o caráter vago das normas econômicas da Constituição gerou uma situação que só poderia vir a alcançar sentido positivo quando o sistema de relações econômicas atuasse de maneira unitária. Do ponto de vista do sistema econômico que se pretendia criar, a solução contemplada na Constituição apontava para uma economia mista, fórmula intermédia, entre a economia liberal e um socialismo de Estado. Contudo, esteve-se longe de estabelecer uma "economia corporativa" ou uma "organização corporativa da economia". Por um lado, garantiu-se a propriedade privada (quer de meios de produção, quer de bens de consumo), mas condicionada por um "interesse geral" representado pelo Estado. Por outro, as corporações econômicas não foram dotadas de funções de disciplina da produção e do mercado (como sugeriram os constituintes defensores da criação dos conselhos econômicos) - e aquelas funções ficariam nas mãos do próprio Estado —- alcançando apenas funções limitadas no campo das relações de trabalho (celebração dos contratos coletivos de trabalho). 


\section{NOTAS}

1 Pode-se apresentar a hipótese de o fato de ter cabido a Salazar a gestão do dossiê da elaboração da nova Constituição ter sido resultado do acaso das circunstâncias políticas. Por outras palavras, a saída de Manuel Rodrigues Júnior do governo para a Faculdade de Direito de Lisboa, em 11 de abril de 1928, o rosto até então mais empenhado nesse processo, teria exigido que outro governante se ocupasse de tal matéria. Ora, o jovem ministro das Finanças, Oliveira Salazar, era, à epoca, figura discreta, com perfil mais acadêmico do que político (cultivando uma postura não partidária), prestigiado pelo programa de equilíbrio orçamental que procurava implementar (Rosas, 2012: 88-108). Dados ainda sua ligação com os meios universitários de direito em Coimbra e Lisboa, sua influência na constituição do Ministério de Domingos de Oliveira e o entrosamento estratégico que mantinha com o presidente da República, Óscar Carmona, não é estranho que tenha ficado com o dossiê do processo constituinte, sendo, de certo modo, uma escolha natural para tal missão em um Executivo dominado por figuras com perfis administrativos e militares.

2 Apesar da ausência de estudos históricos sobre os antecedentes da Carta Constitucional de 1826, sabe-se que, em 1823, o duque de Palmela foi incumbido por d. João VI de criar uma comissão que deveria se ocupar de redigir o projeto constitucional. Essa comissão chegou a se reunir; no entanto, desconhece-se a relação entre o trabalho que terá realizado e o texto outorgado da Carta Constitucional (Canaveira, 1988).

3 Cria-se aqui a proposta "losango" na sequência de uma imagem convocada por Elster, que qualifica os processos constituintes com montagem fechada, mas complementada por consultas públicas a montante e a jusante como procedimentos gerais em forma de "ampulheta" (Eslter, 2012: 169).

4 Optou-se por mencionar, neste artigo, as edições do projeto constitucional a partir da numeração romana que têm os documentos consultados no Arquivo Oliveira Salazar, depositado no Arquivo Nacional da Torre do Tombo (Lisboa). Outra opção segue António de Araújo, que diz serem 13 as versões do estatuto constitucional. 0 autor chega a esse número talvez por considerar autônomas todas as edições, mesmo aquelas que o produtor da documentação considerou serem alterações dentro de uma edição. Na pasta, com a cota atual PT/TT/AOS/CO/ PC-5, existem as seguintes edições: I, sem data e com alterações manuscritas (esta tem outra cópia impressa que contém já no corpo do texto aquelas alterações manuscritas); II, sem data e com alterações manuscritas (esta tem outra cópia impressa com emendas, lendo-se na primeira página que servirá de base às provas distribuídas em Conselho de Ministros); III, em que se lê "Edição a distribuir aos ministros. Servirá às discussões do CM [Conselho de Ministros] (jan. 1932)"; IV, em que se lê "IV Edição: inclusão de emendas aprovadas pelo CM e outras feitas em nova revisão. Para a imprensa em 14-II-32" (essa edição tem outra cópia impressa); $V$, em que se lê " $V$ Edição: Provas mandadas da imprensa em 15-II e novamente revistas. Depois de feitas estas emendas tirou-se a VI Ed. [edição] de 16-II-32"; IV, em que se lê: "16-II-32 (para revisão com o Doutor F. [Fezas] Vital)" (essa edição tem outra cópia impressa em que se lê: "Ed. de 16-II-32 (com as emendas da revisão com os Drs. F. Vital e Martinho Nobre de Melo)"); VII, em que se lê: "Para o Conselho de Ministros de 5-III-1932. Emendas com o Dr. F. Vital; VIII, em que se lê: "Ed. feitas as emendas da 7a Ed. presente ao Conselho de Ministros de 5-III". Finalmente, a IX edição, em que se lê: "Emendada e revista com o Dr. Fezas Vital de 14 a 20 de fevereiro de 1933. Texto enviado à Imprensa Nacional". Essa nona edição tem mais quatro versões diferentes. A segunda, em que se lê: "II Revisão de 14 a 20/II: envolve apenas a II Parte da Constituição". A terceira, em que se lê: "III Revisão de 14 a 20/ll: envolve apenas a I Parte da Constituição". A quarta, em que se lê: "IV Revisão de 14 a 20/ll: envolve toda a Constituição". Por último, a quinta, em que se lê: "V Emendado na revisão do Conselho de Ministros de 22-II-1933: envolve toda a Constituição". 
5 PT/TT/AOS/CO/PC-5: "Constituição" [manuscrito de Salazar], datado de 29 de dezembro de 1931.

6 Para maior desenvolvimento da ideia de que a ordem constitucional portuguesa firmada em 1933 acompanhou alguns modelos constitucionais gerados no pós-Primeira Guerra Mundial em outros Estados europeus (Alemanha, Áustria, Polônia, Estados Bálticos, França), consulte-se: Santos (2015: 77-82).

7 Essa interpretação afasta-se da proposta de Hermínio Martins, que, na literatura existente sobre o período de constitucionalização do regime autoritário português, foi exceção ao avançar com uma leitura crítica sobre as diferenças na formulação desse artigo da Constituição de 1933 em relação ao projeto constitucional submetido à opinião pública em 1932. 0 autor explicou a fórmula final do artigo 50 pela associação do ideário corporativista com o autoritarismo de direita e o fascismo. Dando como exemplos da "espécie política" democrático-corporativa a Constituição brasileira de 1934 (sustentando que continuou a vigorar no sistema instalado em 1946, na ditadura que se the seguiu entre 1964-1985, e novamente na democracia depois de 1985) e a Constituição da IV República Francesa (1946), Martins advogou o "aborto" dessa possibilidade para o caso português. Notando, sem argumentar razões, que Salazar nunca aceitaria tal combinação (deduz-se que imputava as posições do governante a um pensamento autoritário tout court), salientou que "não houve um concurso de forças político-militares para impor uma aproximação a este regime [democrático e corporativo]" (Martins, 2018: 180-181).

8 A essa posição não era alheia a formação que tivera na Faculdade de Direito da Universidade de Coimbra, onde, no ensino da cadeira de economia, desde os anos 1890, apesar de serem estudadas as doutrinas individualistas e socialistas, havia sido cultivado o interesse pela doutrina de List, que subordinava a vida econômica aos objetivos político-nacionais, e pela escola histórica alemã, que defendia que o progresso da economia só poderia ocorrer por via do estudo das instituições de cada povo em particular. Em sua passagem por aquela faculdade, Salazar acompanhou ainda a aproximação da escola intervencionista de Wagner e Schmoller, ensinada sobretudo por Marnoco e Sousa, que sustentava que ao Estado cabia promover o desenvolvimento econômico, intelectual e moral da sociedade, sem indiferença perante a concorrência social, ainda que sem exercer ingerência absorvente (Sousa, 1907: 12-19).

9 PT/TT/AOS/CO/PC-5B: "Correspondência sobre trabalhos preparatórios da Constituição Política [entre Salazar e Afonso Lucas, Mário de Figueiredo e José Alberto dos Reis]", [1932].

10 Durante o período de debate constitucional, a preocupação da hierarquia eclesiástica (apoiada pela Santa Sé) e de algumas personalidades do laicado foi a de tentar modificar o que ficaria inscrito no estatuto constitucional sobre o regime das relações entre o Estado e a Igreja Católica. Católicos com algum tipo de participação política preocuparam-se menos com o modelo de Estado a construir e mais com o protesto sobre 0 estatuto público da Igreja Católica. Publicamente, apenas defenderam propostas concretas relativas à revisão de vários aspectos da Lei de Separação (ensino privado, regime do casamento e do divórcio, bens eclesiásticos, personalidade jurídica da própria Igreja Católica). Meses depois do plebiscito à Constituição, houve círculos católicos que tentaram descortinar qual o espaço de atuação que podiam ter nos organismos corporativos, sobretudo nos sindicatos. Em um segundo momento, após constatação de que o regime não permitia a liberdade sindical e de que a cristianização dos organismos corporativos não seria facilmente tolerada pelo Executivo, denunciaram o afastamento em relação ao modelo de um corporativismo de associação (Arquivo Histórico do Patriarcado de Lisboa. Arquivo Cardeal Cerejeira (AHPL/ACC)/E/02/01/329 e 330). 


\section{FONTES PRIMÁRIAS}

A FUTURA Constituição. Novidades, p. 1, 24 fev. 1933.

ARQUIVO HISTÓRICO DO PATRIARCADO DE LISBOA. Arquivo Cardeal Cerejeira. Cotas atuais: PT/AHPL/ACC/E/02/01/329 e 330: cartas do bispo da Guarda dirigidas ao cardeal Cerejeira, em 9 e 14 de outubro de 1933; AHPL/ACC/R/01/03/007 e 008: questionário apresentado ao sr. subsecretário das Corporações [datado de outubro de 1933, Lisboa, e assinado por Pe Boaventura Alves de Almeida]; [Memorando]: Resumo: A Igreja em face da organização corporativa do Estado Português [7 de novembro de 1933, Lisboa, do Pe Boaventura Alves de Almeida].

ARQUIVO NACIONAL TORRE DO TOMBO. Arquivo Oliveira Salazar. Correspondência Oficial, Correspondência relativa aos trabalhos preparatórios da Constituição Política. Cotas atuais: PT/TT/AOS/CO/PC-5; PT/TT/AOS/ CO/PC-5A; PT/TT/AOS/CO/PC-5B.

CERQUEIRA, Belfort. Constituição. Razões de geral proveito. A Voz, p. 1 e 6, 24 jun. 1932.

COUCEIRO, Henrique Paiva. 0 projeto de Constituição. A Voz, p. 1 e 8, 19 jun. 1932.

GUERRA, Joaquim Mendes. À margem da nova Constituição. Para onde vamos? III. A Voz, p. 1, 26 jun. 1932.

JESUS, Quirino Avelino de. Nacionalismo português. Porto: Empresa Industrial Gráfica, 1932.

MELO, Martinho Nobre de. Para além da revolução. In: Ensaios de filosofia política: estudos morais e sociais. Crítica e doutrina. Lisboa: Livraria Ferin, 1925.

PIMENTA, Alfredo. 0 meu projeto de Constituição. A Voz, p. 1 e 6, 23 jun. 1932.

SALAZAR, António de Oliveira. Discursos 1928-1934. Coimbra: Coimbra, 1935.

SOUSA, Fernando de. Lições de ontem: episódio que importa relembrar. A Voz, p. 1, 30 jul. 1932. . 0 texto da nova Constituição. A Voz, p. 1, 24 fev. 1933.

\section{REFERÊNCIAS BIBLIOGRÁFICAS}

ARAÚJO, António de. A lei de Salazar: estudos sobre a Constituição Política de 1933. Coimbra: Tenacitas, 2007.

BRITO, José Maria Brandão de. Sobre as ideias económicas de Salazar. In: SILVA, A. E. Duarte et al. Salazar e o salazarismo. Lisboa: Publicações Dom Quixote, 1989, p. 35-58.

CAENEGEM, R. G. Van. Uma introdução histórica ao direito constitucional ocidental. Lisboa: Fundação Calouste Gulbenkian, 2009.

CANALES, M. Garcia. La teoría de la representación en la España del siglo XX. Murcia: Universidad de Murcia/Publicaciones del Departamento de Derecho Político, 1977.

CANAVEIRA, Manuel Filipe Cruz. Liberais moderados e constitucionalismo moderado (1814-1852). Lisboa: I.N.I.C., 1988. 
CHORÃO, Luís Bigotte. A crise da república e da ditadura militar. Lisboa: Sextante, 2009.

CUEVAS, Pedro Carlos González. El nacionalismo autoritario (1898-1936). In: MOYA, A. Morales; AIZPURÚA, J. P. Fusi; GUERREIRO, A. de las. Historia de la nación y del nacionalismo español. Barcelona: Fundación Ortega-Marañón/Galaxia Gutenberg/Círculo de Lectores, 2013.

ELSTER, Jon. Forces and mechanisms in the constitution-making process. Duke Law Journal, v. 45, n. 2, p. 364-396, nov. 1995.

The optimal design of a Constituent Assembly. In: LANDEMORE, Hélène; ELSTER, Jon (Ed.). Collective Wisdom: principles and mechanisms. Nova York: Cambridge University Press, 2012, p. 148-172.

GARRIDO, Álvaro. Queremos uma economia nova! Estado Novo e corporativismo. Lisboa: Temas e Debates/ Círculo de Leitores, 2016.

LA CONSTITUCIÓN de Weimar. La Constitución alemana de 11 de agosto de 1919. Madri: Tecnos, 2010.

MARTINS, Hermínio. Reflexões sobre as mudanças de regime em Portugal no século XX: um estudo transcronológico e transnacional. Lisboa: Imprensa de Ciências Sociais, 2018.

MESQUITA, Paulo Dá. Manuel Rodrigues Júnior e o perfil do processo penal português no século XX. Figuras do Judiciário: séculos XIX-XX. Coimbra: Almedina, 2014.

MOREIRA, Vital. Direito corporativo: tópicos das lições do ano letivo de 1971-72 na Faculdade de Direito da Universidade de Coimbra. Coimbra: Unitas/Cooperativa Académica de Consumo, 1973.

MORTATI, Costantino. Una valoración de conjunto sobre la experiencia de la Constitución de Weimar. La Constitución de Weimar: La Constitución alemana de 11 de agosto de 1919. Madri: Editorial Tecnos, 2010.

ROSANVALLON, Pierre. El modelo político francés: la sociedad civil contra el jacobinismo, de 1789 hasta nuestros días. Argentina: Siglo XXI, 2007 [2004].

ROSAS, Fernando. Pensamento e ação política: Portugal século XX (1890-1976). Ensaio histórico. Lisboa: Notícias, 2004.

Salazar e o poder: a arte de saber durar. Lisboa: Tinta da China, 2012.

SANTOS, Paula Borges. A segunda separação: a política religiosa do Estado Novo (1933-1974). Coimbra: Edições Almedina, 2016.

0 modelo político do Estado autoritário português: a ideia corporativa na constitucionalização do regime (1931-1933). Espacio, Tiempo y Forma, n. 27, p. 59-84, 2015.

SCHMITTER, Philippe C. O corporativismo e a política pública em Portugal durante o regime autoritário. Portugal: do autoritarismo à democracia. Lisboa: Imprensa de Ciências Sociais, 1999.

SOUSA, Marnoco; REIS, José Alberto dos. A Faculdade de Direito e o seu ensino. Coimbra: F. França Amado, 1907.

VITAL, Domingos Fezas. Curso de direito corporativo. Lisboa: [s.n.], 1940. 
